\title{
Factors Associated with the Duration of Breastfeeding in the Freiburg Birth Collective, Germany (FreiStill)
}

\author{
Einflussfaktoren auf die Stilldauer im Freiburger Geburtenkollektiv (FreiStill)
}

Authors

Affiliations
R. Rasenack ${ }^{1}$, C. Schneider ${ }^{1}$, E. Jahnz ${ }^{1}$, J. Schulte-Mönting ${ }^{2}$, H. Prömpeler ${ }^{1}$, M. Kunze ${ }^{1}$

${ }^{1}$ University Gynaecological Clinic Freiburg, Freiburg i. Br.

${ }^{2}$ Department of Medical Biometrics and Informatics of the Albert Ludwig University, Freiburg i. Br.

\author{
Schlüsselwörter \\ - Stillen \\ - Entbindungskliniken \\ - Säuglingsernährung \\ - babyfreundliches Kranken- \\ haus \\ - Muttermilch \\ Key words \\ - breastfeeding \\ maternity hospitals \\ - infant nutrition \\ - baby-friendly hospital \\ - lactation
}

received 13.9.2011 revised 24.10.2011 accepted 19.11.2011

\section{Bibliography}

DOI http://dx.doi.org/ 10.1055/s-0031-1280470

Geburtsh Frauenheilk 2012; 72: 64-69 ๑ Georg Thieme

Verlag KG Stuttgart · New York . ISSN 0016-5751

\section{Correspondence}

Dr. Regina Rasenack

Universitätsfrauenklinik

Hugstetterstraße 55

79106 Freiburg

regina.rasenack@

uniklinik-freiburg.de

\section{Abstract \\ $\nabla$}

Purpose: The health benefits of breastfeeding for both infants and mothers are well-documented. The aim of this study was to clarify factors associated with successful breastfeeding.

Methods: We performed a prospective, multicentre cohort study of 443 mothers in person using a standardised questionnaire on postpartum day 1 . Women who had started to breast-feed were interviewed by telephone after 3, 6 and 12 months. A statistical analysis was performed using the SAS system.

Results: $92 \%$ of women (409/443) were initially breastfeeding. After three months the rate decreased to $74 \%$, after six months to $61 \%$ and after 12 months to $28 \%$, respectively. Bivariate analysis revealed a significant positive association with the following factors: maternal age $>35$ years, higher educational level, intention to breastfeed on postpartum day one, high motivation after three months, partner's support of the decision to breastfeed, satisfaction with the care provided in the maternity clinic, a positive breastfeeding experience and follow-up care by a midwife. Elective caesarean delivery, the use of breastfeeding aids, formula supplementation early on and the mother's concern about the amount of milk correlated negatively. Following a multivariate logistic regression analysis, four factors were correlated with having a positive influence on duration of breastfeeding: higher educational level, satisfaction with the care provided within the maternity clinic, follow-up care by a midwife, and a positive current experience of breastfeeding.

Conclusion: Our data demonstrate certain factors successfully influence breastfeeding. Competent care in the maternity clinic, postpartum care by a midwife and a positive experience with breastfeeding increase the rate of breastfeeding and thus have a positive impact on the health of mother and newborn.

\section{Zusammenfassung \\ $\nabla$}

Fragestellung: Die gesundheitlichen Vorteile für Mutter und Neugeborenes durch Stillen sind gut belegt. Die Untersuchung sollte klären, welche Variablen einen Stillerfolg bedingen.

Methode: 443 Mütter wurden in einer prospektiven multizentrischen Kohortenstudie am 1. postpartalen Tag persönlich standardisiert befragt. Frauen, die zu stillen begonnen hatten, wurden nach 3, 6 und 12 Monaten telefonisch interviewt. Die statistische Analyse wurde mit SAS 9 durchgeführt.

Ergebnisse: Die initiale Stillquote lag bei $92 \%$ (409/443). Nach 3 Monaten stillten noch 74\%, nach 6 Monaten $61 \%$ und nach 12 Monaten $28 \%$. Der bivariate Test ergab eine signifikant positive Korrelation zum Stillen für ältere Mütter, längere Ausbildungsdauer, vorbestehende Stillabsicht, starke Stillmotivation nach 3 Monaten, Unterstützung der Stillentscheidung durch den Partner, Zufriedenheit mit der Betreuung in der Geburtsklinik, positives Erleben der Stillerfahrung und Nachsorge durch eine Hebamme. Eine negative Korrelation lag vor für primäre Sectio, Gebrauch von Hilfsmitteln zum Stillen, frühes Zufüttern und Zweifeln an der Milchmenge. In der multivariaten logistischen Regression hatten 4 Variablen einen signifikant positiven Einfluss auf die Stilldauer: längere Ausbildungsdauer, Zufriedenheit mit der Betreuung in der Geburtsklinik, Nachsorge durch eine Hebamme und positives Erleben der aktuellen Stillerfahrung.

Schlussfolgerung: Unsere Untersuchung zeigt, dass es beeinflussbare Faktoren für die Stillbeziehung gibt. Kompetente Betreuung in der Geburtsklinik, Nachsorge durch eine Hebamme und ein positives Erleben des Stillens erhöht die Stillrate und hat somit einen wesentlichen Effekt auf die Gesundheit des Neugeborenen und der Mutter. 


\section{Introduction}

\section{$\nabla$}

In recent years there has been an increase in the number of reports about the importance of breastfeeding for health politics, in industrial countries as well [10]. It has been shown that children who were breastfed have a lower risk of acute otitis media, gastroenteritis, respiratory infections, atopic dermatitis, asthma, overweight, type I and type II diabetes, leukemia, sudden infant death and necrotic enterocolitis, particularly for premature births [11]. A clearly positive effect of breastfeeding on the health of the mother is also acknowledged. Breastfeeding reduces the probability of developing type II diabetes, metabolic syndrome, breast and ovarian cancer and postpartal depression [10,11,25]. The costs of non-breastfeeding compared with six months of breastfeeding for $90 \%$ of all children in the USA in 2001 were estimated to be 13 billion US dollars. A conservative estimate indicates that 911 additional infant deaths could have been prevented [1]. For the realisation of successful breastfeeding the obstetrics team plays a key role in advising and caring for the mother and newborn child during pregnancy, all aspects of the actual childbirth and in the first days postpartum. Hospital care following birth influences the frequency and duration of breastfeeding. In general, together with baby-friendly initiatives of the maternity clinic, the "10 steps for successful breastfeeding" formulated by the WHO and Unicef structure and promote the process of lactation and the duration of breastfeeding $[7,19]$.

After a low point in the frequency of breastfeeding in the 1970s, beginning around 1980 the frequency and duration in Germany began increasing [16].

The objective of the present study was to provide answers to the questions: Which women in the Freiburg birth collective breast fed their children for at least six months after birth? Which socio-demographic variables had positive and which had negative influences upon breastfeeding? What are the influences of the place of birth, type of birth and professional care?

\section{Methods}

\section{$\nabla$}

A prospective, longitudinal multi-centre cohort study was performed within the scope of two doctoral theses [12,21].

Between August and December 2007 the two doctoral candidates interviewed a total of 443 women who had recently given birth to a living child according to a standard format, 219 of these in the University Gynaecological Clinic (Universitäts-Frauenklinik), 216 in the Evangelical Diakonie Hospital (Diakonie-Krankenhaus) and 8 in the Geburtshaus Mayenrain in Freiburg. The study was approved by the ethics commission of the university hospital. The women who had recently given birth were given information in printed form and requested to sign a declaration of consent. Exclusion criteria were age under the age of 18, lacking knowledge of the German language, lack of a telephone, medical contra-indications against breastfeeding and multiple births. The 443 women who had recently given birth comprised approximately one third of the entire number of births in these three facilities during the recruiting period. The University Gynaecological Clinic and the Diakonie Hospital maternity hospitals are accredited by the baby-friendly hospital initiative. The Geburtshaus Mayenrain is under the direction of freelance midwives. The first interview was held at time T0 on the day after giving birth and was conducted by a doctoral candidate in the patient's hospital room. The women from the Geburtshaus were visited at home on the first day after giving birth. Following a preliminary study for the optimisation of the standard interview format the mean time of the first interview was 10 minutes. After three (T1), 6 (T2) and 12 (T3) months the women who had taken up breastfeeding were interviewed by telephone according to a structured format. The last interview was held after the patient had stopped breastfeeding or the child had reached the age of 12 months. The mean time of the telephone interviews at time T1 was 11 minutes, at time T2 7 minutes and after 12 months 6 minutes. Patients who could not be reached by telephone were notified in writing or the attending physician contacted. 11 patients prematurely discontinued their participation in the study: 6 could no longer be reached, 3 relocated to foreign countries outside of Europe, one child was left with a foster family, and one woman decided not to continue participating. The followup quota was thus $97.5 \%$. All "drop outs" were evaluated as having stopped breastfeeding.

The statistical analysis was carried out with the SAS 9 software package. The bivariate analysis took place on the basis of contingency tables and with the aid of the $\mathrm{X}^{2}$ test. The significance limit was defined to be $5 \%$. The logistic regression analysis was carried out as multivariate, binary with backward elimination in order to assess the different variables influencing the results.

\section{Results \\ $\nabla$}

In our collective $92 \%$ (409 of 443 ) took up breastfeeding and $8 \%$ (34 of 443) decided in favour of primary delactation. Bad experience with earlier births was cited as the most frequent reason. At time T1 (after three months) 74\% of the women were still breastfeeding, at time T2 (after six months) 61\% and at time T3 (after 12 months) $28 \%$.

- Fig. 1 shows the decline in the breastfeeding quota as a KaplanMeier curve, with the steepest decline after two months. The most frequent reason why the women beginning breastfeeding stopped this was "presumably too little lactation" (24\%), followed by "the child did not want anymore" (14\%) and "the mother did not want anymore" (14\%). Other reasons were too much stress (11\%), health problems (9\%), breast problems ( $8 \%)$, "it was time to stop" (6\%), breastfeeding confusion (5\%), taking up employment (5\%) and bad experience previously (4\%).

At time T2 (after six months) the bivariate analysis stratifies the status patient continuing breastfeeding versus patient stopped breastfeeding according to the following results ( $\bigcirc$ Table 1 ):

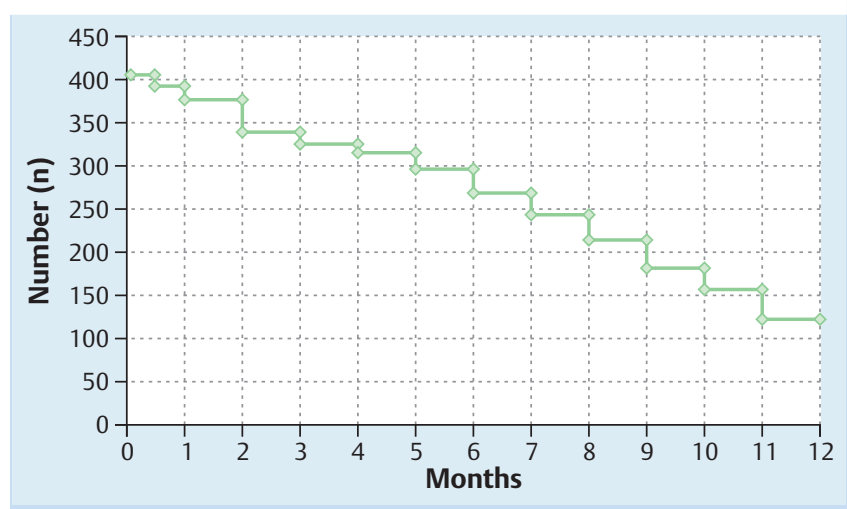

Fig. 1 Number of breastfeeding women from delivery ( 0 months) to 1 year. 
Table 1 Breastfeeding and not breastfeeding at time T2 (after six months).

\begin{tabular}{|c|c|c|c|c|c|}
\hline \multirow[t]{2}{*}{ Parameter } & \multicolumn{2}{|c|}{$\begin{array}{l}\text { Breast- } \\
\text { feeding }\end{array}$} & \multicolumn{2}{|c|}{$\begin{array}{l}\text { Not breast- } \\
\text { feeding }\end{array}$} & \multirow[t]{2}{*}{ p value } \\
\hline & $\mathbf{n}$ & $\%$ & $\mathbf{n}$ & $\%$ & \\
\hline \multicolumn{6}{|l|}{ Age } \\
\hline - 18 to 25 years & 25 & $46.3 \%$ & 29 & $53.7 \%$ & $* *$ \\
\hline 26 to 34 years & 160 & $67.8 \%$ & 76 & $32.2 \%$ & 0.002 \\
\hline - 35 years and older & 85 & $72.7 \%$ & 32 & $27.4 \%$ & \\
\hline \multicolumn{6}{|l|}{ Migratory background } \\
\hline yes & 81 & $60.9 \%$ & 52 & $39.1 \%$ & n.s. \\
\hline$>$ no & 189 & $69.0 \%$ & 85 & $31 \%$ & 0.1322 \\
\hline \multicolumn{6}{|l|}{ Educational level } \\
\hline$><10$ years & 12 & $35.3 \%$ & 22 & $64.7 \%$ & $* * *$ \\
\hline - 10 to 11 years & 126 & $58.6 \%$ & 89 & $41.4 \%$ & $<0.0001$ \\
\hline$>11$ years & 127 & $83 \%$ & 26 & $17 \%$ & \\
\hline \multicolumn{6}{|l|}{ Premature birth } \\
\hline$>$ yes & 24 & $55.8 \%$ & 19 & $44.2 \%$ & n.s. \\
\hline no & 246 & $67.6 \%$ & 118 & $32.4 \%$ & 0.1695 \\
\hline \multicolumn{6}{|l|}{ Gravidity } \\
\hline 1 & 127 & $69.8 \%$ & 55 & $30.2 \%$ & n.s. \\
\hline$>>1$ & 143 & $63.6 \%$ & 82 & $36.4 \%$ & 0.2241 \\
\hline \multicolumn{6}{|l|}{ Parity } \\
\hline$>1$ & 146 & $67.9 \%$ & 69 & $32.1 \%$ & n.s. \\
\hline$>>1$ & 124 & $64.6 \%$ & 68 & $35.4 \%$ & 0.5463 \\
\hline \multicolumn{6}{|l|}{ Mode of delivery } \\
\hline Spontaneous & 136 & $68.7 \%$ & 62 & $31.3 \%$ & \\
\hline Vag. operative & 19 & $73.1 \%$ & 7 & $26.9 \%$ & \\
\hline $\begin{array}{l}\text { Compelled } \\
\text { caesarean section }\end{array}$ & 69 & $71.1 \%$ & 28 & $28.9 \%$ & $*$ \\
\hline $\begin{array}{l}\text { Elective caesarean } \\
\text { section }\end{array}$ & 46 & $53.5 \%$ & 40 & $46.5 \%$ & 0.038 \\
\hline \multicolumn{6}{|l|}{ Previous experience } \\
\hline - Positive & 99 & $72.3 \%$ & 38 & $27.7 \%$ & $* *$ \\
\hline > Mixed & 19 & $63.3 \%$ & 11 & $36.7 \%$ & \\
\hline Negative & 5 & $26.3 \%$ & 14 & $73.7 \%$ & 0.004 \\
\hline $\begin{array}{l}\text { No supplementa- } \\
\text { tion on 1st day of life }\end{array}$ & 236 & $68.8 \%$ & 107 & $31.2 \%$ & $*$ \\
\hline - Glucose solution & 10 & $58.8 \%$ & 7 & $41.2 \%$ & 0.0434 \\
\hline $\begin{array}{l}\text { Formula supple- } \\
\text { mentation }\end{array}$ & 24 & $51.1 \%$ & 23 & $48.9 \%$ & \\
\hline $\begin{array}{l}\text { Breastfeeding aids } \\
\text { on 1st day of life }\end{array}$ & 57 & $53.3 \%$ & 50 & $46.7 \%$ & $* *$ \\
\hline $\begin{array}{l}\text { No breastfeeding } \\
\text { aids }\end{array}$ & 213 & $71 \%$ & 87 & $29 \%$ & 0.001 \\
\hline $\begin{array}{l}\text { Pacifier at age } \\
3 \text { months }\end{array}$ & 178 & $60.5 \%$ & 116 & $39.5 \%$ & $* * *$ \\
\hline No pacifier & 87 & $80.6 \%$ & 21 & $19.4 \%$ & 0.0003 \\
\hline $\begin{array}{l}\text { Breastfeeding } \\
\text { planning on 1st day } \\
\text { of life }\end{array}$ & 242 & $69.5 \%$ & 106 & $30.5 \%$ & $* *$ \\
\hline $\begin{array}{l}\text { Breastfeeding } \\
\text { not planned }\end{array}$ & 28 & $47.5 \%$ & 31 & $52.5 \%$ & 0.0015 \\
\hline
\end{tabular}

\begin{tabular}{|c|c|c|c|c|c|}
\hline \multirow[t]{2}{*}{ Parameter } & \multicolumn{2}{|c|}{$\begin{array}{l}\text { Breast- } \\
\text { feeding }\end{array}$} & \multicolumn{2}{|c|}{$\begin{array}{l}\text { Not breast- } \\
\text { feeding }\end{array}$} & \multirow[t]{2}{*}{ p value } \\
\hline & $\mathbf{n}$ & $\%$ & $\mathbf{n}$ & $\%$ & \\
\hline \multicolumn{6}{|l|}{$\begin{array}{l}\text { Experience with } \\
\text { breastfeeding at T1 }\end{array}$} \\
\hline - Positive & 224 & $75.2 \%$ & 74 & $24.8 \%$ & $* * *$ \\
\hline Mixed & 19 & $52.8 \%$ & 17 & $47.2 \%$ & \\
\hline Negative & 22 & $32.4 \%$ & 46 & $67.7 \%$ & $<0.0001$ \\
\hline Coincides at T1 & 199 & $76.8 \%$ & 60 & $23.2 \%$ & $* * *$ \\
\hline Does not coincide & 66 & $46.2 \%$ & 77 & $53.9 \%$ & 0.0005 \\
\hline \multicolumn{6}{|l|}{$\begin{array}{l}\text { Motivation for } \\
\text { breastfeeding }\end{array}$} \\
\hline Very strong & 164 & $89.6 \%$ & 19 & $10.4 \%$ & $* * *$ \\
\hline T1 strong & 82 & $77.4 \%$ & 24 & $22.6 \%$ & \\
\hline Less or weak & 18 & $50 \%$ & 18 & $50 \%$ & $<0.0001$ \\
\hline $\begin{array}{l}\text { Doubting amount } \\
\text { of milk }\end{array}$ & 22 & $39.3 \%$ & 34 & $60.7 \%$ & $* * *$ \\
\hline No doubt at T1 & 242 & $89.6 \%$ & 28 & $10.4 \%$ & $<0.0001$ \\
\hline Support of partner & 215 & $69.6 \%$ & 94 & $30.4 \%$ & $*$ \\
\hline No support & 45 & $54.2 \%$ & 38 & $45.8 \%$ & 0.018 \\
\hline Diseased mother & 36 & $62.1 \%$ & 22 & $37.9 \%$ & n.s. \\
\hline - Allergy & 42 & $63.6 \%$ & 24 & $36.4 \%$ & \\
\hline - Not diseased & 191 & $68.2 \%$ & 89 & $31.8 \%$ & 0.7131 \\
\hline $\begin{array}{l}\text { Postpartal } \\
\text { depression }\end{array}$ & 7 & $46.7 \%$ & 8 & $53.3 \%$ & n.s. \\
\hline - No depression at T1 & 258 & $66.7 \%$ & 129 & $33.3 \%$ & 0.1849 \\
\hline - Healthy new-born & 243 & $68.5 \%$ & 112 & $31.5 \%$ & n.s. \\
\hline $\begin{array}{l}\text { Congenital } \\
\text { abnormality }\end{array}$ & 3 & $42.9 \%$ & 4 & $57.2 \%$ & \\
\hline - Acute disease & 3 & $37.5 \%$ & 5 & $62.5 \%$ & 0.1004 \\
\hline - Transfer to NICU & 17 & $51.5 \%$ & 16 & $48.5 \%$ & n.s. \\
\hline - No separation & 253 & $67.7 \%$ & 121 & $32.4 \%$ & 0.0915 \\
\hline \multicolumn{6}{|l|}{ Place of birth } \\
\hline University & 121 & $60.2 \%$ & 80 & $39.8 \%$ & $* *$ \\
\hline - Diakonie Hospital & 141 & $71.2 \%$ & 57 & $28.8 \%$ & \\
\hline Geburtshaus & 8 & $100 \%$ & 0 & & 0.008 \\
\hline Satisfied with care & 217 & $69.1 \%$ & 97 & $30.9 \%$ & $*$ \\
\hline $\begin{array}{l}\text { Not satisfied with } \\
\text { care }\end{array}$ & 52 & $56.5 \%$ & 40 & $43.5 \%$ & 0.0340 \\
\hline \multicolumn{6}{|l|}{ Postpartal care } \\
\hline By midwife & 207 & $67 \%$ & 102 & $33 \%$ & $* *$ \\
\hline No midwife & 8 & $34 \%$ & 15 & $66 \%$ & 0.0021 \\
\hline \multicolumn{6}{|l|}{ Postpartal care } \\
\hline - Positive & 234 & $69.4 \%$ & 103 & $30.6 \%$ & $* *$ \\
\hline Negative & 31 & $47.7 \%$ & 34 & $52.3 \%$ & 0.0012 \\
\hline
\end{tabular}

n. s.: not significant, ${ }^{*}$ significant, ${ }^{* *}$ highly significant, ${ }^{* * *}$ very highly significant.

Children born after a normal time of pregnancy tend to still be breastfed after six months ( $37+1$ week of pregnancy). However, in view of the low number of premature births $(n=43)$ this difference is not significant.

Older women frequently continue breastfeeding for a statistically significant longer time than younger mothers.

Mothers without a migratory background breast fed more frequently for up to six months than women of migratory background. This difference indicates a tendency however it is not statistically significant.

A decisive factor is the level of education. $64.7 \%$ of women not completing their schooling or only with a secondary school education, $41.4 \%$ of women with a school leaving certificate and only $17 \%$ of women with 11 or more years of education stopped breastfeeding after 6 months.

The influence of the number of pregnancies and the parity is not significant.

In respect of the mode of birth, a statistically significant negative correlation is recognisable for primary caesarean delivery.

The influence of subjective experiences with the breastfeeding of a previous child is significant. Women with positive earlier experiences are more likely to breastfeed another child than women with mixed earlier experiences or altogether negative experiences.

The breastfeeding situation on the first postpartal day has a considerable influence upon the duration of breastfeeding. Women 
who, following birth, can nourish their babies on the breast alone frequently breastfeed their children for longer than six months. When glucose solution is orally administered in addition, the percentage of children breastfed over a longer time is lower. With formula supplementation nutrition the percentage of children breastfed longer than six months declines significantly.

The correlation between the use of breastfeeding aids (such as milk pumps, bottle feeding, nipple shields or mamilliforms) on the first day after birth and the duration of breastfeeding is also statistically significant. When no breastfeeding aids are required, the percentage of children breastfed for longer than six months is greater than for newborn children requiring breastfeeding aids.

A highly significant correlation was found for children who are given a pacifier (dummy) at the age of three months. Children without a pacifier are more frequently breastfed longer than six months than children who are given a pacifier.

The correlation of the intention to breastfeed on the day after birth with a longer duration of breastfeeding is statistically significant. Women who fully intend to breastfeed are far more likely to breastfeed after six months than those not planning to breastfeed.

If the breastfeeding period is positively experienced after three months there is a greater probability of breastfeeding children for longer than six months. When this is experienced only positively, many children are still breastfed after six months. With mixed experiences the number is less. With largely negative experiences with breastfeeding after three months, only relatively few children are breastfed longer than six months.

When the actual experience of breastfeeding coincides with expectations after three months, this also has a positive influence on the duration of breastfeeding.

The motivation after three months shows a statistically significant correlation with the duration of breastfeeding. Very strongly motivated women frequently breastfeed for longer than six months; whereas poorly motivated women rarely breastfeed their children longer than six months.

A highly significant factor is uncertainty on the part of the mother whether the amount of milk produced at time T1 (after three months) is sufficient or not. When there is no doubt the majority of mothers breastfeed longer than six months and when there is uncertainty only $39.3 \%$ of the women.

When the partner supports the decision to breastfeed there is a recognisable correlation with longer durations of breastfeeding. Compared with women whose partners do not support the decision to breastfeed, women with supportive partners are more likely to breastfeed their children longer than six months.

No statistically significant correlation exists between an illness of the mother and the duration of breastfeeding.

A postpartum depression was diagnosed with 15 women at the time of the interview after three months. Seven of these women breastfed their children longer than six months, compared with the majority of women without postpartum depression. In view of the small number of cases, this difference is not significant.

As with prematurely born children the probability of stopping breastfeeding for children with other peculiarities, such as congenital abnormalities or diseases, after up to six months is greater. Compared with healthy children, the majority of whom are breastfed longer than six months, less than half of the children with congenital abnormalities and even less children with other diseases were breastfed for longer than six months. Here again, in view of the small number of cases this difference is not statistically significant.
A consideration of the place of birth can be correlated with the duration of breastfeeding. Children born in the University Gynaecological Clinic are less frequently breastfed longer than six months than children born in the Diakonie Hospital. This difference is significant and results from the different patient groups. The duration of breastfeeding was longer for all children born in the Geburtshaus Mayenrain. However, in view of the small number of cases $(n=8)$ no statistical evaluation is possible.

Women who were satisfied with the care provided by the maternity hospital were more likely to breastfeed longer than six months than women who were not satisfied with the care provided. The postpartum follow-up care also influences the duration of breastfeeding. Women with postpartum care by a midwife showed a higher probability of breastfeeding longer than six months. When women experienced the postpartum care positively the percentage breastfeeding their children six months was significantly higher than for women with an unsatisfactory postpartum care situation.

In the multivariate logistic regression two variables were found to have an independent significant positive influence and two variables a negative influence on the duration of breastfeeding:

1. Whether the mother has studied more than 11 years ( $p=<0.0001$, odds ratio 3.927, 95\% CI 2.350-6.562),

2. satisfaction with the care in the maternity hospital ( $p=0.0050$, odds ratio $2.091,95 \%$ CI 1.250-3.499),

3. no postpartum care by a midwife ( $\mathrm{p}=0.0144$, odds ratio 0.307 , 95\% CI 0.119-0.790), and

4. negative experience with breastfeeding $(\mathrm{p}=0.0287$, odds ratio 0.433, 95\% CI 0.204-0.917).

\section{Discussion}

\section{$\nabla$}

$8 \%$ of the women in our Freiburg birth collective of 2007 decided in favour of primary delactation. This rate agrees roughly with the statistics given in the literature for Germany. The SuSe study of 1717 children born in Germany in 1997/1998 [14] reported a primary delactation rate of $9 \%$. More recent data from Bavaria [15] report a primary delactation rate of $10.5 \%$ for 3822 participating women. A significantly different primary delactation rate of only $3 \%$ was reported for 2005 children born in a Hamburg hospital [4]. This conspicuously low delactation rate can possibly be attributed to the particular group of women giving birth in a hospital located in a prosperous neighbourhood.

While the initiation rate for breastfeeding is high in our study a significant decline was observed in the further course of the study, most noticeably after around eight weeks ( $\bullet$ Fig. 1 ). Nevertheless, the breastfeeding quota of $74 \%$ after three months is significantly higher than the 65\% reported in 1998 [14] and the 65\% reported in Bavaria [15]. In our collective $61 \%$ of the mothers are still breastfeeding after six months, while the SuSe study reported $48 \%$ and the Bavarian data reported $52 \%$.

Our study indicates that even after 12 months $28 \%$ of the infants are at least partly breastfed. By comparison, the study of 10 years ago reported that this had declined to $13 \%$ [14]. Following the low point of the breastfeeding frequency in the 1970s and a renaissance of breastfeeding in the 1980s and 1990s, there are now indications of a possible trend to longer durations of breastfeeding. The most frequently given reasons for stopping breastfeeding revealed by our study were too little lactation (23\%) and the child or mother did not want anymore (14\% each). Identical figures of $14 \%$ of mothers and of children who did not want breastfeeding 
anymore were reported in the Hamburg study [23]. In this study also, the most important reason given was not having sufficient milk (44\%).

In our collective older mothers breastfed longer than six months significantly more frequently than younger women. This effect is apparent in all published studies, for example in the prospective cohort study on breastfeeding in Bavaria [22] or in a Canadian cohort study with 856 mother-child pairs published in 2006 [2].

Women with a migratory background practice primary delactation less frequently, but often feed over a shorter time. Comparisons with other studies are very difficult, as the composition of the collectives is very different and this factor can have very different influences on adapting to the country of immigration. A similar result was also described in the Bavarian study, with longer durations of breastfeeding for mothers born in Germany [22]. The sole demographic factor was the level of education of the mother, which was also shown to be highly significant in the multivariate analysis. Women with the qualification to undertake university studies breastfeed significantly longer than women with a secondary school education or women not completing their schooling. This effect is observed in all studies [2,15,20,22]. For the 43 premature births in our study collective a tendency towards breastfeeding shorter than six months was observed. In view of the small number of cases, this difference is not statistically significant. In the Bavarian study the adjusted odds ratio for the primary delactation of premature births was reported as 3.04 [15]. Establishing satisfactory breastfeeding following a premature birth thus appears to be a particular challenge. A case control study of interest from the Netherlands reported a $63 \%$ rate of breastfed prematurely born infants released early from hospital care with a stomach tube, compared with only $36 \%$ for prematurely born infants following a longer hospital stay [18]. The positive influence of a high level of education for the mother on the breastfeeding of prematurely born infants ( $60 \%$ of very small prematurely born infants were exclusively breastfed when discharged) is reported in a study from Denmark [27]. Exclusively breastfeeding a prematurely born infant is more difficult than the breastfeeding of a child born after a normal pregnancy, but is particularly positive for the child's healthy development. The literature reports lower breastfeeding rates for prematurely born infants compared with infants born after a normal pregnancy, for example in the Bavarian study of Kohlhuber et al. [15].

Positive experience with the breastfeeding of previous children appears to favour longer durations of breastfeeding in women who have borne children previously. Thus, for example, Schwegler et al. [22] report a statistically significant correlation between longer durations of breastfeeding and mothers who have experience with breastfeeding. By contrast, our study indicates that there is no relevant difference between women pregnant for the first time and women who have previously borne children.

Our study revealed the influence of the mode of birth on breastfeeding. Spontaneously delivered children, vaginally operative deliveries, and secondary caesarean deliveries show a high percentage of breastfeeding for longer than six months. Children delivered by elective caesarean section showed a statistically significant lower rate of breastfeeding for more than six months. A possible explanation for this difference could be the higher number of ill children, premature births and mothers with pre-existing problems which preclude breastfeeding [9,24]. Another possibility could be the influence of the lower endogenic release of oxytocin in the group of women delivering by elective caesarean section. An enhanced rate of prematurely stopped breastfeeding has also been reported in Italy by Zanardo et al. [28] and by Haugen et al. in Norway [8]. As found in our study, the Bavarian study [22] reports a longer duration of breastfeeding for spontaneously delivered children; in the multivariate analysis, however, this was no longer significant. However, in this study only two groups were formed: spontaneously delivered children versus vaginally operative and elective and secondary caesarean section deliveries in a single category. In the present study the mode of birth had no independent significant influence on the duration of breastfeeding (see multivariate analysis).

The negative influences of formula supplementation in the first days of the infant's life and of problems and the necessity of breastfeeding aids has been described many times in the literature. In the Bavarian study [22] breastfeeding aids during the first days of the infant's life and problems with breastfeeding showed a highly significant correlation with shorter durations of breastfeeding. The negative influences of formula supplementation during the first days and of using a pacifier are also reported in the USA studies $[3,6]$. The Norwegian study also shows the negative influence of formula supplementation during the first days of life [8]. These data prove that formula supplementation during the first days of life must in any case be made dependent upon existing medical indications and may in no case represent a routine procedure. The observation of shorter durations of breastfeeding when breastfeeding aids are used in the first days of life can certainly be due to the existence of problems and has also been reported in other studies $[17,20]$.

As was found in our study, a significant negative correlation between the use of a pacifier and the duration of breastfeeding was also found in other studies [20,22]. However, Schwegler et al. and Roig et al. investigated the use of a pacifier in the first days of the infant's life; that is, in the phase of initiating breastfeeding. In our study we investigated the influence of a pacifier at the age of three months.

It is understandable that women who experience breastfeeding positively breastfeed their children longer than women who experience problems with breastfeeding. The positive correlation is significant in both the bivariate and the multivariate analysis. Decisive for the well-being of the mother and child is the absence of stress and doubts. The vicious circle created by the very common doubts about the amount of milk and the resulting stress which restricts the release of oxytocin and the ensuing inhibition of the let-down reflex is problematical.

The importance of the partner's support of breastfeeding has been frequently described in the literature. The Bavarian study [15] and the Hamburg study [13] indicated the clear influence of the partner's support on the duration of breastfeeding.

Mothers who are ill without medical reasons for rejecting breastfeeding should be helped to breastfeed satisfactorily. For mothers with postpartum depression a complex interaction may possibly exist between breastfeeding, breastfeeding problems and the outbreak of the illness. The observation that depressive mothers stop breastfeeding earlier is supported by a number of published studies $[2,5,26]$.

The differences between women giving birth to children in the University Gynaecological Clinic, the Diakonie Hospital and the midwives' practice revealed by our study are certainly attributable to differences in the groups of mothers at the different places. The multivariate analysis shows that the place of birth has no independent significant influence upon successful breastfeeding. The multivariate analysis shows a significant correlation between the duration of breastfeeding and satisfaction with the 
care provided by the maternity hospital. In the Bavarian study [22] a positive correlation was found between outpatient birth and a longer duration of breastfeeding. The positive correlation was attributed to a larger percentage of women with greater interest in questions of health in the group of women with outpatient child delivery. Equally relevant is the follow-up care by a midwife. This positive correlation with a longer duration of breastfeeding was shown by the multivariate analysis.

\section{Conclusions}

Our study clearly shows the effects of different variables on breastfeeding. These factors can be influenced and include: more information about healthy infant nutrition and the disadvantages of not breastfeeding, particularly for young parents and relatively uneducated social segments, the creation of a satisfactory puerperium atmosphere, avoiding supplemental nutrition without medical indication in the first days of life, and dispelling doubts concerning the amount of breast milk. The care provided by the maternity hospital should be provided by properly trained personnel (midwives, obstetricians and paediatric specialists) to the satisfaction of the mother, so that positive experiences promote breastfeeding. Following the normally brief hospital stay and the midwife's support of and advice to the mother, the advice of gynaecologists and neonatologists with experience in breastfeeding is also urgently required.

\section{Impact for Clinical Practice}

\section{$\nabla$}

Gynaecologists must have a well-founded knowledge of the advantages and management of breastfeeding. Particularly experience-based care should be possible in the following situations: with young mothers, women from relatively uneducated social segments, illness or separation of the mother from the newborn infant, and following caesarean deliveries.

\section{Acknowledgements}

We wish to express our sincere gratitude to Professor Walter Schuth for his advice with the development of the standard interview format and discussion of the results. Our thanks are also due to Ms. Heike Tröndle for the preparation of the manuscript.

\section{Conflict of Interest}

\section{$\nabla$}

The authors declare that there are no financial connections to any company in relation to this publication.

\section{References}

1 Bartick M, Reinhold A. The burden of suboptimal breastfeeding in the United States: a pediatric cost analysis. Pediatrics 2010; 125: e10481056

2 Clifford TJ, Campbell MK, Speechley KN et al. Factors influencing full breastfeeding in a southwestern ontario community: assessments at 1 week and at 6 months postpartum. J Hum Lact 2006; 22: 292-304

3 Declercq E, Labbok MH, Sakala C et al. Hospital practices and women's likelihood of fulfilling their intention to exclusively breastfeed. Am J Public Health 2009; 99: 929-935

4 Deneke C, Scheele M. QuaSti - Qualität im Stillfreundlichen Krankenhaus. Frauenarzt 2007; 48: 369-372
5 Dennis $C L$, McQueen $K$. Does maternal postpartum depressive symptomatology influence infant feeding outcomes? Acta Paediatr 2007; 96: 590-594

6 DiGirolamo AM, Grummer-Strawn LM, Fein SB. Effect of-care practices on breastfeeding. Pediatrics 2008; 122 (Suppl. 2): S43-S49

7 Haager-Bürkert H, Niebuhr D, Kroke A et al. Perceived difficulties for clinics with maternity units in Germany in obtaining the certification "baby friendly hospital". Geburtsh Frauenheilk 2010; 70: 726-731

8 Haggkvist AP, Brantsaeter AL, Grjibowski AM et al. Prevalence of breastfeeding in the Norwegian Mother and Child Cohort Study and health service-related correlates of cessation of full breast-feeding. Public Health Nutr 2010; 13: 2076-2086

9 Hartge DR, Dawson A, Bohlmann MK et al. Gravidas with a BMI above 25: challenges in antenatal and peripartal monitoring. Geburtsh Frauenheilk 2010; 70: 463-471

10 Ip S, Chung M, Raman G et al. Breastfeeding and maternal and infant health outcomes in developed countries. Evid Rep Technol Assess (Full Rep) 2007; 153: 1-186

11 Ip S, Chung M, Raman G et al. A summary of the Agency for Healthcare Research and Quality's evidence report on breastfeeding in developed countries. Breastfeed Med 2009; 4 (Suppl. 1): S17-S30

12 Jahnz E-M. Einflüsse und Bedingungen während der Stillzeit für Mutter und Kind im Freiburger Geburtenkollektiv. Freiburg: Albert-LudwigsUniversität, Medizinische Fakultät; 2012

13 Jöllenbeck $M$, Deneke C, Seibt AC et al. Unterstützungswünsche für das Stillen. Stillen und Stillbereitschaft. Frauenarzt 2009; 6: 515-518

14 Kersting M, Dulon M. Assessment of breast-feeding promotion in hospitals and follow-up survey of mother-infant pairs in Germany: the SuSe Study. Public Health Nutr 2002; 5: 547-552

15 Kohlhuber M, Rebhan B, Schwegler U et al. Breastfeeding rates and duration in Germany: a Bavarian cohort study. Br J Nutr 2008; 99: 11271132

16 Lange C, Schenk L, Bergmann R. Ergebnisse des Kinder- und Jugendsurveys (KiGGS). Verbreitung, Dauer und zeitlicher Trend des Stillens in Deutschland. Bundesgesundheitsbl 2007; 50: 624-633

17 McKechnie AC, Eglash A. Nipple shields: a review of the literature. Breastfeed Med 2010; 5: 309-314

18 Meerlo-Habing ZE, Kosters-Boes EA, Klip A et al. Early discharge with tube feeding at home for preterm infants is associated with longer duration of breast feeding. Arch Dis Child Fetal Neonatal Ed 2009; 94: F294-F297

19 Merten S, Dratva J, Ackermann-Liebrich U. Do baby-friendly hospitals influence breastfeeding duration on a national level? Pediatrics 2005; 116: e702-e708

20 Roig AO, Martinez MR, Garcia JC et al. Factors associated to breastfeeding cessation before 6 months. Rev Lat Am Enfermagem 2010; 18: 373-380

21 Schneider C. Soziodemographische Bedingungen im Freiburger Entbindungskollektiv und deren Einflüsse auf Stillen und Ernährung des Säuglings, Freiburg: Albert-Ludwigs-Universität, Medizinische Fakultät; 2010

22 Schwegler U, Kohlhuber M, Twardella D et al. Einfluss der Stillbedingungen in den ersten Lebenstagen auf die Dauer des ausschließlichen Stillens. Geburtsh Frauenheilk 2008; 68: 607-614

23 Seibt A, Deneke C, Juppe-Schütz T et al. Wirksamkeit eines babyfreundlichen Krankenhauses aus Sicht der Nutzerinnen. Laktation und Stillen 2008; 1 : 12-18

24 Simoes E, Kunz SK, Münnich R et al. Informed consent for cesarean delivery: method-associated morbidity gradients require the participation of pregnant women. Geburtsh Frauenheilk 2010; 70: 732-738

25 Stuebe $A$. The risks of not breastfeeding for mothers and infants. Rev Obstet Gynecol 2009; 2: 222-231

26 Watkins S, Meltzer-Brody S, Zolnoun D et al. Early breastfeeding experiences and postpartum depression. Obstet Gynecol 2011; 118 (2 Pt 1): 214-221

27 Zachariassen G, Faerk J, Grytter C et al. Factors associated with successful establishment of breastfeeding in very preterm infants. Acta Paediatr 2010; 99: 1000-1004

28 Zanardo V, Svegliado G, Cavallin F et al. Elective cesarean delivery: does it have a negative effect on breastfeeding? Birth 2010; 37: 275-279

Deutschsprachige Zusatzinformationen mit deutschem Text online abrufbar unter: www.thieme-connect.de/ejournals/toc/gebfra. 